\title{
Trabalho, educação e linguagem
}

\section{Work, education and language}

\author{
Lígia Regina Klein*
}

\begin{abstract}
RESUMO
O debate atual acerca da reestruturação produtiva e seu impacto na educação tem discutido o papel desempenhado pelo desenvolvimento científicotecnológico nas mudanças correntes. Entre os recursos tecnológicos destacam-se as novas linguagens articuladas às Novas Tecnologias e aos Meios de Comunicação de Massa. Este trabalho analisa - com a preocupação de distinguir o que realmente constitui uma novidade de fundo na estrutura capitalista e o que é o velho sob novas formas de aparências - as relações entre trabalho, educação e linguagem nesse quadro de mudanças. Para tanto, discute, com ênfase na emergência do trabalhador coletivo, as implicações dos processos de divisão do trabalho e desenvolvimento da maquinaria para a formação do trabalhador individual. No interior desses processos articulados, na sua configuração mais contemporânea, são analisados dois possíveis lócus de ambigüidade na referência à linguagem, os quais permitem formulações de conteúdo ideológico, caracterizados pela fetichização das novas tecnologias.

Palavras-chave: Linguagens e tecnologia, competências comunicativas, linguagens e educação.
\end{abstract}

\begin{abstract}
The present debate on the productive restructuring and its impact on education has been discussing the role played by the technological-scientific development on the current changes. Among the technological resources the new languages articulated to the New Technologies and to the Means of

* Doutora em História e Filosofia da Educação pela PUC/SP. Professora e pesquisadora do Programa de Pós-Graduação em Educação da Universidade Federal do Paraná. Projeto financiado pelo CNPq e FAP, no âmbito do Plano Sul de Pesquisa e Pós-Graduação. ppge@ufpr.br/lrklein@ipnet.com.br
\end{abstract}


Communication of Mass are outstanding. The present work analyzes - with the concern for distinguishing what really constitutes a backstage reality into the capitalist structure, and what is old under new appearance ways the relationship between work, education and language into this picture of changes. Thus, it discusses, with emphasis on the emergency for the collective work, the implications of the processes of work division and the development of the machinery for the formation of the individual worker. Two possible lócus of ambiguity with reference to the language are analyzed within these articulated processes, in their most contemporaneous configuration, which allow formulations of ideological content, characterized by the fetish making of the new technologies.

Key-words: languages and technology, communicative competences, languages and education.

\section{Introdução}

Vivemos um momento em que as relações entre educação e trabalho, muitas vezes secundarizadas nas produções teóricas, vêm assumindo um papel bastante significativo no palco dos debates sobre educação. Esse fenômeno é alavancado pelas importantes mudanças que se verificam no processo de produção e que impactam diretamente a educação.

De fato, a emergência de novas questões, ou a necessidade de enfrentamento mais conseqüente de velhos dilemas - reais ou aparentes -, tem dado origem, no Brasil, a uma vasta produção teórica que discute as demandas postas à educação pelas mudanças em curso no "mundo do trabalho" (KUENZER, 1997; 1998; 1999; 2001; MACHADO, 1992; FRIGOTTO, 1992; 2001; FERRETI, 1994, entre outros).

Essa produção se constrói sob o peso de dois fatores, entre outros: a urgência com que se impõe a discussão e a abrangência das questões a serem investigadas, obrigando a incursão em áreas científicas distintas. Disto resulta um conjunto muito amplo e relativamente novo de informações, conceitos e reflexões nessas produções, resultando, por vezes, em dificuldade significativa para a apreensão do seu conteúdo por leitores e interlocutores pouco familiarizados com as categorias empregadas, levando-os, não raro, a algumas conclusões apressadas, bem como alguns simplismos e ambigüidades decorrentes do emprego deslocado de terminologia não específica da área ou, mesmo, da atribuição de novo conteúdo a 
um termo já consagrado - como denunciam, por exemplo, BENKO (1999) e FERRETI (1994). É o caso, por exemplo, de algumas discussões sobre as novas linguagens postas em curso no processo de mudanças - decorrentes da abertura econômica e da reestruturação produtiva - do mundo do trabalho, e que demandariam novas competências para o trabalhador. $\mathrm{O}$ objetivo deste trabalho é traçar algumas considerações acerca da incorporação dessa terminologia no debate atual, bem como buscar elementos para a possível superação de algumas ambigüidades e conclusões atinentes às novas demandas postas à educação, entre as quais, especialmente, aquelas relativas ao caráter de novidade do processo deflagrado pela atual configuração do trabalho.

\section{O papel da tecnologia no processo capitalista de produção e na reestruturação produtiva: o velho e o novo}

O debate acerca da reestruturação produtiva e seu impacto na educação aponta, acertadamente, para o papel desempenhado pelo desenvolvimento científico-tecnológico nas mudanças correntes. Entretanto, algumas vezes sugere-se que esse papel constitui uma novidade decorrente do processo atual de reestruturação, quando, na verdade, uma das características marcantes da sociedade capitalista, desde sua consolidação, é a incorporação direta da ciência à produção, na forma de desenvolvimento tecnológico e de organização do processo de trabalho, como necessidade, mesma, do capitalismo. Dizendo de outro modo, a necessidade da reprodução ampliada do capital, articulada à pressão da concorrência, estão na base da organização do trabalho e do revolucionamento tecnológico demandados pelo capitalismo, desde suas origens.

É sabido que o capital se alimenta do trabalho excedente, isto é, daquele tempo de trabalho em que o trabalhador produz além do necessário para a sua reprodução própria e de sua família. A produção de trabalho excedente supõe que a jornada do trabalhador se divida em dois tempos: em um deles, o trabalhador produz o necessário para seu próprio consumo e de sua família; no outro, produz um excedente que é apropriado pelo seu patrão, ou seja, pelo proprietário dos meios de produção. Essa extensão da jornada de trabalho, de forma a produzir trabalho excedente, denomina-se 
mais valia absoluta. A expansão da mais valia absoluta, ou seja, do tempo de trabalho excedente, esbarra em um limite concreto, seja porque o dia não tem mais que 24 horas, seja porque não é possível manter o trabalhador em atividade ininterrupta durante todas as horas do dia. A necessidade permanente de reprodução do capital, entretanto, impõe uma solução para esse limite, promovendo, assim, a forma característica de exploração capitalista: a mais valia relativa, que se caracteriza, não pelo aumento da jornada de trabalho, mas pela diminuição, no interior de uma mesma jornada, do tempo de trabalho necessário para a reprodução do trabalhador e de sua família. Assim, reduzindo-se o tempo de trabalho necessário, amplia-se, proporcionalmente, o trabalho excedente, sem alteração da jornada de trabalho. A diminuição do tempo de trabalho necessário (e conseqüente aumento do trabalho excedente) só é possível mediante o incremento da produtividade, o que implica, segundo Marx, entre outras circunstâncias, "a destreza media dos trabalhadores, o grau de desenvolvimento da ciência e sua aplicação tecnológica, a organização social do processo de produção, o volume e a eficácia dos meios de produção e as condições naturais" (MARX, 1982, p. 47).

Se, na sua origem, o capital submeteu o trabalho a seu talante nas condições técnicas existentes à época, a busca de mais valia relativa levou ao desencadeamento de uma revolução dessas condições, a fim de aumentar a força produtiva do trabalho. Mais ainda, a constante necessidade de aumento da produtividade tornou também constante o revolucionamento das ditas condições. Marx e Engels ensinam, a esse respeito:

A burguesia só pode existir se constantemente revolucionar os meios de produção e, portanto, as relações de produção e, com elas, todas as relações sociais. (...) A subversão contínua da produção, o constante abalo de todo o sistema social, a permanente agitação e insegurança distinguem a época burguesa de todas as precedentes (MARX; ENGELS, 1998).

Como se vê, o desenvolvimento cada vez mais acelerado dos meios de produção — onde a tecnologia tem lugar destacado - constitui uma demanda inerente ao capitalismo, não sendo, portanto, nenhuma novidade.

Da mesma forma, não constituem novidade a dimensão universal que o capitalismo assumiu, bem como a importância da informação para esse 
processo de globalização. Marx e Engels já afirmavam, com toda clareza, essa direção do desenvolvimento capitalista:

A necessidade de expansão constante do mercado impele a burguesia a estender-se por todo o globo. Necessita estabelecer-se em toda parte, explorar em toda parte, criar vínculos em toda parte.

(...) Graças ao vertiginoso desenvolvimento dos meios de produção e às facilidades incríveis dos meios de comunicação, a burguesia consegue atrair irresistivelmente todas as nações, mesmo as mais atrasadas, para seu modelo de civilização. Sua mercadoria barata constitui sua arma mais poderosa, capaz de destruir até as muralhas da China e de submeter os bárbaros mais arredios ao domínio estrangeiro. Com mão férrea, obriga todas as nações a adotarem um modo burguês da produção, sob pena de desaparecerem se não o aceitarem; força-as a optarem pelo que ela chama de civilização, ou, em outras palavras, a se aburguesarem. Em suma, visa formar o mundo à sua imagem e semelhança (MARX; ENGELS, 1998, p. 11).

Entretanto, é igualmente evidente que as formas e a intensidade das mudanças constituem novidade a ser criteriosamente analisada, não apenas pelas demandas postas à educação, como pela possibilidade de constituírem elementos da realidade a intervir na própria estrutura do modelo capitalista de produção, haja visto o pressuposto dialético da passagem da quantidade à qualidade.

Com efeito, como ensina Lênin, a questão fulcral do conhecimento revolucionário é apreender o que, na realidade concreta, está nascendo e o que está morrendo; o que constitui conteúdo velho (sob velha ou nova forma) e o que constitui conteúdo novo (sob forma nova ou aparentemente velha). Para tal conhecimento é importante apreender a distinguir as dimensões de conteúdo e forma, sob pena de estarmos tomando, como novo, um velho dado da realidade, ou, como velho, o novo. É esta preocupação que norteia o presente trabalho. 


\section{Divisão social do trabalho sob a forma capitalista de produção: emergência do trabalhador coletivo e suas implicações na forma- ção do trabalhador individual}

A produção da massa de conhecimentos que a humanidade acumula ao longo de sua história, bem como a produção das habilidades e capacidades que vão compondo a progressiva possibilidade humana de intervenção na realidade, repousam na atividade produtiva e constituem os conteúdos da educação. Daí a íntima relação existente, desde os primórdios da história humana, entre educação e trabalho.

É ao produzir os bens necessários à satisfação de suas necessidades - materiais e espirituais - que os homens se defrontam prática e teoricamente com os elementos e processos da natureza e da sociedade. Com efeito, para poder agir sobre esses elementos e processos, transformandoos tanto quanto a produção da existência o exige, os homens precisam desenvolver habilidades, condições técnicas e conhecimentos. Por outro lado, ao mesmo tempo em que a sua ação sobre a natureza e a sociedade lhe permite e exige interpretar e conhecer esses elementos e processos, a massa de conhecimentos acumulados orienta a ação, permitindo o aperfeiçoamento ou mesmo a superação dos conhecimentos, práticas e aparato tecnológico até então existentes. Conclui-se, daí, que a atividade produtiva constitui um processo em que teoria e prática apresentam-se imbricadas, interdependentes e reciprocamente determinantes.

No processo de trabalho, a elaboração integral de um produto pelo mesmo trabalhador exige que este realize sucessivas e diferentes atividades, as quais requerem diferentes conhecimentos e habilidades: em uma, desenvolverá mais a força, noutra, a habilidade, noutra ainda, a atenção e o cálculo, etc. Daí resulta que esse indivíduo veja-se, por força do trabalho, diante da necessidade e, ao mesmo tempo, de condições de desenvolver múltiplas capacidades e conhecimentos. Em outros termos, o trabalhador que desenvolve integralmente um produto opera nas diversificadas etapas de sua produção e, por decorrência, desenvolve atividades diversificadas às quais correspondem conhecimentos e habilidades também diversificados.

Entretanto, sob o modo de produção capitalista, a relação teoria-eprática se apresenta de modo substancialmente diferente em razão da fragmentação do processo de trabalho e a consequiente separação entre o trabalhador e o produto do trabalho. 
Enquanto nos modos de produção anteriores a divisão social do trabalho se restringia aos ramos da produção, sob o capitalismo ela se caracteriza, cada vez mais, por uma radical parcelarização do processo produtivo envolvido na realização de um mesmo produto. Deste modo, a organização do trabalho, sob o capital, obedece a uma lógica que se caracteriza pela constituição, cada vez mais desenvolvida, do trabalhador coletivo, entendido enquanto somatório de inúmeros trabalhadores parciais (ou seja, trabalhadores que realizam apenas uma parcela das atividades que compõem o processo integral de produção de um dado produto). Como esclarece ROSDOLSKY (2001, p. 209), “o capital é, desde o primeiro momento, uma 'força coletiva' baseada na supressão do isolamento do trabalhador, na concentração de muitos trabalhadores sob o comando de um capitalista". A constituição dessa força coletiva se explica, por um lado, pela tendência do capital de empregar o maior número possível de trabalhadores para poder extrair mais mais-trabalho (ROSDOLSKY, 2001, p. 211) e, por outro, pelo processo de desenvolvimento dos mecanismos (instrumentos e organização do trabalho) de aumento da produtividade e se caracteriza por uma mudança substancial na forma de divisão do trabalho.

Diferentemente da divisão do trabalho tal como se realizava nas formações econômicas anteriores, a partir da manufatura se institui e se consagra, como conteúdo específico do modo capitalista de produção, a forma de divisão calcada na separação entre o produtor e o produto do trabalho, em razão da fragmentação das etapas da produção até sua decomposição em atividades muito simples. De fato, o trabalhador realiza apenas uma parcela do conjunto de atividades demandadas por determinado produto. Assim, não produz nenhuma mercadoria, mas participa de um momento, apenas, dessa produção. São tantos os indivíduos que participam da produção e é tão parcial e restrita a atividade que realizam (relativamente à totalidade do processo), que cada trabalhador não se reconhece, ou não reconhece sua parcela de participação quando se defronta com o produto acabado. Nesta nova forma de divisão do trabalho, são processos concomitantes e interdependentes a socialização e a parcelarização do trabalho; o processo de produção social do conhecimento e o estreitamento e deformação da habilidade manual e capacidade intelectual do trabalhador individual. Os conhecimentos e habilidades necessários para a produção passam a ser exigidos e produzidos pela unidade mais ampla de produção e, em contrapartida, deixam de ser requeridos do trabalhador individual. Ou seja, passam a ser propriedade do capital, ao tempo em que são expropriados do trabalhador individual, conforme expõe Marx, ainda comentando a produção manufatureira: 
"O que perdem os trabalhadores parciais, concentra-se no capital que se confronta com eles. A divisão manufatureira do trabalho opõe-lhes as forças intelectuais do processo material de produção como propriedade de outrem e como poder que os domina" (MARX, 1982, p. 413).

Temos, assim, contraditoriamente, o desenvolvimento sem paralelo de um conjunto amplo e orgânico dos conhecimentos e práticas envolvidos no processo produtivo levado a cabo pelo trabalhador coletivo, a par de um brutal minguamento do conhecimento, habilidades e vontade do trabalhador individual. Assim traduz Marx essa contradição: “... o enriquecimento do trabalhador coletivo e, por isso, do capital, em forças produtivas sociais, realiza-se às custas do empobrecimento do trabalhador em forças produtivas individuais" (MARX, 1982, p. 414).

Nessa dissociação entre o produtor e o produto, desde a cooperação simples à indústria, passando pela manufatura, o capitalista representa, diante do trabalhador isolado, a unidade e a vontade do trabalhador coletivo.

Observa-se, então, na sociedade capitalista, uma contradição nas relações entre o trabalhador coletivo e o trabalhador individual; entre o desenvolvimento teórico-prático do trabalhador coletivo e o desenvolvimento teórico-prático do trabalhador individual, em que a expropriação, em todos os sentidos, deste último é a condição mesma de desenvolvimento do trabalhador coletivo.

A divisão técnica do trabalho implica, por um lado, a redução do trabalhador individual a uma função única, teórica e praticamente limitada, na qual ele se especializa e passa a desenvolver com o máximo de virtuosidade. ${ }^{1} \mathrm{~A}$ contrapartida dessa virtuosidade - que decorre da exclusividade e repetição constante da mesma atividade - é a impossibilidade de desenvolvimento de quaisquer outros conhecimentos e habilidades alheios a essa atividade exclusiva. De fato, esta forma de divisão do trabalho, como explicita Marx,

...deforma o trabalhador monstruosamente, levando-o artificialmente a desenvolver uma habilidade parcial, à custa da repressão de um mundo de instintos e capacidades produtivas, lembrando aquela prática das regiões platinas, onde se mata um animal apenas para tirar-lhes a pele ou o sebo. Não só o trabalho é dividido e suas diferentes frações distribuídas entre os

1 "A estreiteza e as deficiências do trabalhador parcial tornam-se perfeições quando ele é parte integrante do trabalhador coletivo", enfatiza MARX (1982, p. 412). 
indivíduos, mas o próprio indivíduo é mutilado e transformado no aparelho automático de um trabalho parcial (MARX, 1982, p. 412).

Por outro lado, essa divisão técnica do trabalho permite o desenvolvimento pleno (também, teórica e praticamente) do trabalhador coletivo, ao tornar a produção independente dos conhecimentos e habilidades individuais:

O trabalhador coletivo passa a possuir então todas as qualidades produtivas no mesmo grau elevado de virtuosidade e as despende ao mesmo tempo de maneira mais econômica, individualizando todos os seus órgãos em trabalhadores especiais ou em grupos de trabalhos aplicados em suas funções específicas (MARX, 1982, p. 400).

Esses produtos da divisão do trabalho, tipicamente capitalistas - a limitação e deformação do trabalhador parcial e a constituição do trabalhador coletivo, detentor, na máxima virtuosidade, de todo conhecimento e habilidade - têm impacto determinante na organização burguesa da educação. Com efeito, na medida em que fazem emergir, por um lado, uma hierarquia de funções e, por outro, uma classificação dos trabalhadores em hábeis e inábeis, a divisão e a objetivação do trabalho determinam a estrutura hierárquica da educação, ao mesmo tempo em que reduzem sua demanda.

O processo de divisão do trabalho, sob a forma capitalista, separa, torna independentes e isola as diversas operações demandadas na elaboração de um produto e também, de forma articulada, separa, classifica e agrupa os trabalhadores segundo suas qualidades naturais dominantes. Acrescente-se que tal separação se refere, não apenas às diversas etapas da atividade manual, mas, igualmente, separa a atividade manual da atividade intelectual. Tal separação, classificação e agrupamento determina a separação, classificação e agrupamento de novas tipologias de trabalhadores, agora não mais distinguidos pela sua arte, mas pela especialização de sua atividade, as quais se enquadram em um novo formato de hierarquia, no corpo do trabalhador coletivo. Neste novo cenário, a formação dos trabalhadores se organiza em termos dessa classificação e correspondentemente a essa hierarquia. Diz Marx, a respeito: "As diferentes funções do trabalhador coletivo são simples ou complexas, inferiores ou superiores, e seus órgãos, as 
forças individuais de trabalho, exigem diferentes graus de formação..." (MARX, 1982, p. 401).

Entretanto, diferentemente do que ocorria no trabalho artesanal, onde se requeria sempre um conjunto diversificado de habilidades, a organização capitalista do trabalho, articulada ao desenvolvimento tecnológico, vai criando, também, uma classe de trabalhadores dos quais não se requer qualquer destreza especial: os trabalhadores inábeis - cuja maior qualidade é, na verdade, a ausência de qualquer habilidade específica. De fato, o trabalho requer desde habilidades mais complexas até certos manejos simples que qualquer pessoa é capaz de realizar. A decomposição do processo de trabalho em inúmeras atividades simples, ao separar as funções mais simples das mais complexas, tornando independente a realização de umas e de outras, torna capazes, ou seja, aproveitáveis para o trabalho, mesmo os sujeitos inábeis, mesmo os sujeitos que, sob a forma artesanal do trabalho, seriam recusados por absoluta inabilidade, conforme explicita Marx:

Em todo ofício de que se apossa, a manufatura cria uma classe de trabalhadores sem qualquer destreza especial, os quais o artesanato punha totalmente de lado. Depois de desenvolver, até atingir a virtuosidade, uma única especialidade limitada, sacrificando a capacidade total de trabalho do ser humano, põe-se a manufatura a transformar numa especialidade a ausência de qualquer formação (MARX, 1982, p. 401).

Assim, a divisão técnica do trabalho vai requerer e produzir duas categorias de trabalhadores: os hábeis e os inábeis. Por seu turno, os trabalhadores hábeis se classificam segundo uma hierarquia de funções. Verificase, portanto, uma dupla classificação dos trabalhadores: uma, fundada na necessidade ou não de habilidades e outra - referente ao conjunto dos trabalhadores hábeis -, fundada na hierarquia das funções.

Essa classificação dos trabalhadores orienta a demanda de educação para o capital, conforme esclarece Marx: "ao lado da graduação hierárquica, surge a classificação dos trabalhadores em hábeis e inábeis. Para os últimos, não há custos de aprendizagem, e, para os primeiros, esses custos se reduzem em relação às despesas necessárias para formar um artesão, pois a função deles foi simplificada" (MARX, 1982, p. 402).

Para os inábeis - que constituem a maioria significativa do conjunto de trabalhadores requeridos pelo capitalismo - o capital vê-se contingenciado 
a prover apenas os rudimentos civilizatórios e o aprendizado da disciplina, da obediência e dos valores morais indispensáveis ao exercício da dominação, o que se realiza, em grande parte, por mecanismos alheios à escola (a família, a mídia, a religião etc.).

A educação que transcende tais rudimentos pode restringir-se aos hábeis, ou seja, àqueles trabalhadores que exercem funções hierarquicamente qualificadas, que requerem certas habilidades. Posto que os trabalhadores hábeis se classificam, como já vimos, segundo uma hierarquia de funções requeridas pela produção, a qual, por sua vez, se assenta em uma hierarquia de habilidades especializadas, também o sistema de ensino especificamente destinado aos trabalhadores se estrutura na forma de uma organização que "distribui" parcimoniosa, hierárquica e especializadamente aos trabalhadores hábeis, os conhecimentos e as habilidades requeridos pela sua função parcial enquanto membros do trabalhador coletivo.

A formação do trabalhador hábil se organiza de modo que, sob o controle do capital e sobre uma base comum - que contempla conteúdos sociais civilizatórios, o aprendizado da disciplina, da obediência e dos valores morais indispensáveis ao exercício da dominação -, a massa de conhecimentos e habilidades detidas pelo trabalhador coletivo às custas da expropriação dos trabalhadores individuais é "redistribuída" de forma não universal, mas hierárquica e especializadamente conforme os níveis e nichos especializados de trabalhadores.

\section{A maquinaria: objetivação do trabalho e suas implicações na for- mação do trabalhador individual}

Como vimos antes, a constituição do trabalhador coletivo faz-se mediante a expropriação dos conhecimentos e habilidades do trabalhador individual. Entretanto, ao lado da divisão do trabalho, desencadeada pela manufatura, essa expropriação se realiza, também, através da crescente objetivação do trabalho realizado pela indústria moderna, isto é, pela transferência da atividade laboral do trabalhador para a máquina, processo esse que constitui o conteúdo das transformações tecnológicas produzidas pelo capitalismo. Como esclarece Marx: "Na manufatura, o ponto de partida para revo- 
lucionar o modo de produção é a força de trabalho, na indústria moderna, o instrumental de trabalho" (MARX, 1982, p. 424).

No uso de ferramentas, o trabalhador conjuga a força mecânica e o movimento apropriado a um determinado fim, ou seja, a habilidade (entendida enquanto domínio do movimento e conhecimentos correlatos para a consecução de um determinado fim). A revolução industrial, segundo Marx, "apodera-se primeiro desta segunda parte da ferramenta e deixa para o ser humano, no começo, a função puramente mecânica de força motriz, ao lado do novo trabalho de vigiar a máquina e corrigir com a mão seus erros". Posteriormente, a máquina dispensa, inclusive, a força motriz, reservando ao trabalhador quase exclusivamente a função de vigiar a máquina e corrigir seus erros.

Se a manufatura limita e deforma o trabalhador, submetendo-o à atividade fragmentada, a indústria, com a objetivação do trabalho, leva ao extremo essa limitação e deformação, produzindo o que Marx denominou de patologia industrial. Em seus termos:

Certa deformação física e espiritual é inseparável mesmo da divisão do trabalho na sociedade. Mas, como o período manufatureiro leva muito mais longe a divisão social do trabalho e também, com sua divisão peculiar, ataca o indivíduo em suas raízes vitais, é ele que primeiro fornece o material e o impulso para a patologia industrial (MARX, 1982, p. 416).

Ocorre, no processo de objetivação do trabalho, uma expropriação ainda mais radical da habilidade do trabalhador, pois, como ensina Marx, "com a ferramenta que se transfere à máquina segue a virtuosidade desenvolvida pelo trabalhador em seu manejo" (MARX, 1982, p. 480). Desse modo, a indústria mecanizada promove um nivelamento dos trabalhos que os operários - agora meros auxiliares das máquinas - têm que executar e, assim, dissolve a hierarquia dos trabalhadores especializados. A fronteira entre os hábeis e os inábeis torna-se cada vez mais tênue ampliando o contingente destes últimos.

Posto que a educação destinada aos trabalhadores restringe-se aos hábeis, como vimos acima, entende-se a razão do aumento da massa de trabalhadores para os quais o capital considera supérflua qualquer formação. 
Considerando-se o crescente desenvolvimento tecnológico, ao lado da manutenção das mesmas relações de produção inerentes ao capitalismo - vale dizer, a propriedade privada dos meios de produção e o assalariamento - conclui-se que, sob o ponto de vista da qualificação, acentua-se o processo de nivelamento dos trabalhadores, para baixo, em virtude da homogeneização do trabalho, ampliando-se tanto o exército de inábeis quanto o exército de excluídos do processo produtivo.

Nesse sentido, tais relações de produção soam falsas, pois sem fundamento em uma análise mais consistente da realidade concreta, as considerações sobre as perspectivas atuais da formação do trabalhador, constantes do documento Parâmetros Curriculares Nacionais - Ensino Médio, do Ministério de Educação:

A centralidade do conhecimento nos processos de produção e organização da vida social rompe com o paradigma segundo o qual a educação seria um instrumento de "conformação" do futuro profissional ao mundo do trabalho. Disciplina, obediência, respeito restrito às regras estabelecidas, condições até então necessárias para a inclusão social, via profissionalização, perdem a relevância, face às novas exigências colocadas pelo desenvolvimento tecnológico e social.

A nova sociedade, decorrente da revolução tecnológica e seus desdobramentos na produção e na área da informação, apresenta características possíveis de assegurar à educação uma autonomia ainda não alcançada. Isto ocorre na medida em que o desenvolvimento das competências cognitivas e culturais exigidas para o pleno desenvolvimento humano passa a coincidir com o que se espera na esfera da produção.

O novo paradigma emana da compreensão de que, cada vez mais, as competências desejáveis ao pleno desenvolvimento humano aproximamse das necessárias à inserção no processo produtivo. Segundo Tedesco, aceitar tal perspectiva otimista seria admitir que vivemos "uma circunstância histórica inédita, na qual as capacidades para o desenvolvimento produtivo seriam idênticas para o papel do cidadão e para o desenvolvimento social". Ou seja, admitindo tal correspondência entre as competências exigidas para o exercício da cidadania e para as atividades produtivas, recoloca-se o papel da educação como elemento de desenvolvimento social.

Em contrapartida, é importante compreender que a aproximação entre as competências desejáveis em cada uma das dimensões sociais não garante uma homogeneização das oportunidades sociais. Há que considerar a redução dos espaços para os que vão trabalhar em atividades simbólicas, em que o conhecimento é o instrumento principal, os que vão continuar 
atuando em atividades tradicionais e, o mais grave, os que se vêem excluídos (MEC, 1999, p. 23).

Em primeiro lugar, não há elementos concretos para fundamentar a afirmação de que é, hoje, irrelevante para o capitalismo a inculcação, no espírito dos trabalhadores, de valores como a obediência e o respeito às regras estabelecidas, ou a internalização do disciplinamento necessário à atividade fragmentada e repetitiva, imposta pela divisão social do trabalho. Para que tal fato acontecesse, seria necessária a superação das relações de produção capitalistas, calcadas na exploração e dominação, e toda sua récua de horrores, miséria e embrutecimento ou, ao contrário, sua vitória tão radical a ponto de inviabilizar qualquer tentativa de resistência dos trabalhadores.

Também é desprovida de fundamentação a idéia de que o desenvolvimento das competências cognitivas e culturais exigidas para o pleno desenvolvimento humano tenham passado a coincidir com o que se espera na esfera da produção. Como vimos, a divisão técnica do trabalho, articulada à automação do processo produtivo, torna cada vez menos exigidos do trabalhador individual quaisquer conhecimentos e habilidades mais complexos.

A própria fragilidade das afirmações leva o texto a uma incoerência óbvia, quando, no último parágrafo citado, a realidade concreta é, finalmente, levada em consideração e afirma-se a desigualdade das oportunidades sociais, a "redução dos espaços para os que vão trabalhar em atividades simbólicas", e a existência de "excluídos". Ora, admitidos tais dados da realidade, deduz-se a inviabilidade de uma educação que promova "as competências desejáveis ao pleno desenvolvimento humano", para o conjunto dos trabalhadores ou, mesmo, para uma parcela significativa da população trabalhadora. 


\section{Comunicação no interior do organismo coletivo de produção e no processo social de produção: um possível locus de ambigüidade no emprego do termo linguagem}

Um outro aspecto importante que se verifica na produção mecanizada é o desaparecimento do princípio subjetivo da divisão do trabalho, vigente até a manufatura. Mesmo sob a intensa fragmentação das etapas do trabalho e a intensa simplificação da atividade individual que tiveram lugar no período manufatureiro, a habilidade do trabalhador, por simplificada que fosse, era exigida: cada operação parcial precisava ser executada manualmente pelo operário, a quem cabia aplicar determinado instrumento ao objeto do trabalho, imprimindo-lhe o movimento apropriado. Para isso, a despeito da fragmentação do trabalho, cada etapa do processo era ajustada ao trabalhador e à sua habilidade. Sob a maquinaria, entretanto, esse princípio subjetivo é superado, quer no que se refere aos movimentos parciais, quer na própria organização do processo de trabalho social, segundo ensina Marx: "Na manufatura, a organização do processo de trabalho social é puramente subjetiva, uma combinação de trabalhadores parciais. No sistema de máquinas, tem a indústria moderna o organismo de produção inteiramente objetivo, que o trabalhador encontra pronto e acabado como condição material de produção." (MARX, 1982, p. 440).

Para Marx, na maquinaria "o problema de levar a cabo cada um dos processos parciais e de entrelaçá-los é resolvido com a aplicação técnica da mecânica, da química, etc." (MARX, 1982, p. 433).

Depreende-se, dessa afirmação, que a objetivação do trabalho se realiza em dois sentidos, interdependentes: na execução de cada processo parcial e na comunicação entre os processos parciais, de forma a entrelaçá-los em uma articulação ininterrupta, da primeira à última etapa. Depreende-se, ainda, dessa afirmação, que em ambos os sentidos o problema se resolve através da aplicação técnica da mecânica, da química etc., ou seja, do desenvolvimento técnico-científico. "A conversão do instrumental de trabalho em maquinaria exige a substituição da força humana por forças naturais e da rotina empírica pela aplicação consciente da ciência”. (MARX, 1982, p. 433)

Em outras palavras, a produção, na grande indústria, requer uma tecnologia que realize, sem a intervenção do trabalhador, cada processo parcial, bem como a comunicação - transmissão - entre os processos parciais. Com efeito, a maquinaria desenvolvida consiste em três partes, a 
saber: o motor, a transmissão e a máquina-ferramenta. Se esta última se apodera do objeto do trabalho e, através de determinadas operações (cortar, prensar etc.), transforma-o de acordo com o fim desejado, é a transmissão que regula o movimento implicado nas operações, definindo-lhe a forma (circular, perpendicular, plana etc.).

A grande indústria, fundada na maquinaria, consuma a separação entre as forças intelectuais do processo de produção e o trabalho manual. Seu desenvolvimento, por sua vez, demanda uma constante evolução tecnológica das três partes integrantes da maquinaria, entre as quais destacamos, para efeito deste artigo, a transmissão ou comunicação entre os processos parciais da produção. Essa demanda é apreendida por Marx, ao explicar a automação: "quando a máquina-ferramenta, ao transformar a matéria-prima, executa sem ajuda humana todos os movimentos necessários, precisando apenas da vigilância do homem para uma intervenção eventual, temos um sistema automático, suscetível, entretanto, de contínuos aperfeiçoamentos" (MARX, 1982, p. 434).

Entretanto, a revolução desencadeada pela maquinaria tornou necessário também um revolucionamento do processo social de produção, ou seja, dos meios de comunicação e de transporte:

Os meios de transporte e de comunicação, legados pelo período manufatureiro, logo se tornaram obstáculos insuportáveis para a indústria moderna com sua velocidade febril de produção em grande escala, seu contínuo deslocamento de massas de capital e de trabalhadores de um ramo de produção para outro e com as novas conexões que criou no mercado mundial (MARX, 1982, p. 438).

Observa-se, portanto, no desenvolvimento do modo capitalista de produção, um processo em que se articulam o desenvolvimento, por um lado, dos meios de comunicação no interior do processo de trabalho (ou seja, os processos de transmissão no interior do sistema de máquinas) e, por outro, dos meios de comunicação social (a comunicação e/ou as trocas entre os homens). A forma altamente desenvolvida que essa tecnologia - as Novas Tecnologias e os Meios de Comunicação de Massa, como é conhecida alcançou nos dias atuais é apenas uma conseqüência previsível do movimento intrínseco do capital. 
Cabe destacar, todavia, que embora se trate de processos de comunicação de naturezas distintas, seu imbricamento nas transformações ocorridas no processo produtivo parece estar ensejando, nos discursos sobre reestruturação produtiva, confusões (intencionais ou não) que se traduzem sob a expressão novas linguagens.

A primeira forma de comunicação acima mencionada constitui, evidentemente, a objetivação da transmissão do movimento - regulado conforme a forma necessária ao fim desejado -, de uma força motriz à máquina-ferramenta - cuja máquina-ferramenta, por sua vez, imprime sobre o objeto a operação necessária ao mesmo fim.

A complexidade alcançada pelo desenvolvimento da maquinaria, na atualidade, e a conseqüente simplificação e fragmentação das relações entre a força motriz, a transmissão e a máquina-ferramenta demandam formas cada vez mais complexas de automação, cuja feição atual materializa-se na informatização e automação flexível, de base microeletrônica. Paralelamente, tem lugar a simplificação cada vez maior da atividade intelectual e manual do trabalhador. A este, efetivamente, cabe vez mais exclusivamente, a vigilância das máquinas e eventual intervenção, em caso de falha no processo.

Da mesma forma que a articulação - em um movimento contínuo, ininterrupto - de todos os movimentos e operações demandados pela produção se realiza, na forma mais avançada e predominantemente, pela informatização do processo, com base na microeletrônica, também, por seu turno, a comunicação social, cuja extensão e ritmo se alteraram em face de necessidades postas pela própria extensão e ritmo da produção, encontra seu recurso mais avançado de transmissão no mesmo recurso tecnológico.

O uso, em ambos os casos, de um recurso técnico similar (a informatização computacional) pode estar gerando a falsa percepção, como já mencionamos, de alguma identidade entre os dois processos de comunicação. O equívoco, no caso, é tomar-se a forma - melhor dizendo, neste caso, o veículo - pelo conteúdo.

$\mathrm{Na}$ automatização do processo fabril, a comunicação, no interior do sistema de máquinas, é trabalho morto, atividade humana já realizada, cristalizada em um conjunto mecânico e fixo de informações articuladas, às quais o maquinário "responde" mecanicamente. Tal é, também, o entendimento de MACHADO (1992), na seguinte passagem: "O saber vivo do trabalho é encampado pela lógica conceitual formalista, que o sintetiza, codifica e o congela ao transformá-lo em 'softwares' a mais nova expressão do trabalho morto" (com grifos no original). 
A linguagem, entretanto, é atividade humana viva, atividade de produção dialógica de sentido, para o qual concorrem as condições de produção do discurso, a saber, os interlocutores, o contexto histórico-social e os meios e recursos da interlocução. Naquela, a resposta é sempre prevista no quadro de uma programação bem definida e, o que é mais importante, alimentada por uma base de dados fornecidos à máquina pelo homem. Nesta, a presença da vontade, da intenção, do interesse põe em jogo a contradição, a ambivalência, o subentendido, o implícito e supõe a possibilidade de respostas inusitadas e, portanto, não sujeitas a inventário prévio por enumeração. Como afirma VOGT (1979, p. 71), "sabemos que cada enunciação pode ter uma multiplicidade de significações e que as intenções do falante, ao produzir um enunciado, podem ter variações de tal ordem que tornem quase uma caricatura a pretensão de atribuir-lhes uma única e verdadeira interpretação".

Ora, o uso indiferenciado do termo linguagem, tanto para referir-se à comunicação humana, como para designar a programação do processo de transmissão no interior da maquinaria - lembremos as "linguagens" utilizadas na computação - revela mais uma das inúmeras formas ideológicas de confusão entre trabalho vivo e trabalho morto. Não por acaso, a reflexão lingüística que se desenvolve ao longo do capitalismo toma como objeto de seu estudo, conforme denuncia Volochinov, ${ }^{2}$ a língua morta-escrita-estrangeira, ou ainda, toma "a enunciação isolada-fechada-monológica, desvinculada de seu contexto lingüístico e real, à qual se opõe, não uma resposta potencial ativa, mas a compreensão passiva do filólogo" como o ponto de partida da reflexão lingüística (BAKHTIN, 1986, p. 99).

A identidade do recurso técnico não legitima a percepção, como já mencionamos, de uma identidade entre os dois processos de comunicação. A denominação comum eleva à estatura de linguagem a mera programação da transmissão mecânica da força e da forma do movimento à máquinaferramenta. Correspondentemente, reduz a forma tipicamente humana de interação social - a linguagem - a simples ato mecânico de transmissão de idéias ou informações. Reduz, ainda, a atividade humana à mera reação programada. Temos aqui o que, em uma analogia, poderíamos denominar de fetichismo das novas tecnologias.

2 Considerando o avanço das discussões acerca da polêmica sobre a verdadeira autoria da obra Marxismo e Filosofia da Linguagem, inclinamo-nos por atribuir essa autoria a Volochinov. 
Defendendo a clareza das categorias da linguística, Mounin trata da importância, na ciência, da definição clara dos termos, criticando um certo discurso dos biólogos, conforme se depreende do trecho abaixo:

Concebemos que os lingüistas reprovem e desaconselhem o uso imoderado e a priori da palavra linguagem para descrever fenômenos, sem uma investigação científica prévia. Corre-se assim o risco de postular que há uma intenção de comunicação em casos em que essa intenção está ausente. Também não sabemos se os biólogos não se arriscam a desorientar-nos e a desorientarem-se a si próprios quando nos falam do ácido desoxirribonucléico como emissor de uma "linguagem" que envia "mensagens" ao citoplasma, mensagens estas que são ordens provenientes de um "código" cujas "letras" (ou fonemas?) são quatro bases azotadas que servem para a construção de vinte "palavras" (quer dizer, vinte ácidos aminados) cujas combinações produzem "frase" (quer dizer proteínas) que transportam a "informação" genética. Em vez de termos lingüísticos que aqui parecem não ser mais que metáforas, graças às quais não raro se diz e acredita que "existe algo de escrito no coração da matéria", seria prudente falar, apenas, em termos de transmissão (e nem sequer de comunicação). As mesmas utilizações metafóricas permitiriam, sem dúvida, com um pouco de engenho, descrever toda a circulação ferroviária em termos de linguística estrutural, sem benefício teórico para a lingüística ou para o funcionamento dos caminhos de ferro (MOUNIN, 1968, p. 41).

Analogia semelhante - e igualmente reducionista -, que compara o processo de pensamento no cérebro humano com o processamento de informações no computador, proposta por John von Neumann e por Herbert Simon, é denunciada por TENÓRIO (1998). Dreyfus, citado por Tenório, na mesma obra, desmascara os princípios em que se fundamenta tal analogia, quais sejam:

a. tese biológica de que, em algum nível, o cérebro processa informações por agentes biológicos que ligam e desligam "interruptores";

b. tese psicológica de que a mente opera à base de bits de informação segundo procedimentos bem definidos; 
c. pressuposto epistemológico de que todo conhecimento pode ser formalizado especialmente através da álgebra booleana;

d. pressuposto ontológico de que o existente é um conjunto de fatos (informações), cada um independente de outro (p. 4-5).

Essa "coisificação" ou naturalização das relações humanas, através de metáforas ou identificações ilegítimas, é recurso comum no discurso ideológico, prestando-se, graças ao deslocamento de conteúdo, ao ocultamento dos fundamentos das relações humanas. Destaque-se, ainda, nos princípios acima, a negação do caráter de totalidade orgânica à realidade.

\section{Linguagem, signos e códigos: outro possível locus de imprecisão}

O uso impreciso do termo linguagem é denunciado freqüentemente pelos lingüistas. Para LOPES (2000, p. 35), “o termo 'linguagem' apresenta uma notável flutuação de sentido, prestando-se aos usos mais diversos. Ele é comumente empregado para designar, indiferentemente, fenômenos tão afastados quanto a linguagem dos animais, a linguagem falada, a linguagem escrita, a linguagem das artes, a linguagem dos gestos". LYONS (1985) inicia seu livro Linguagem e Linguística com um capítulo em que refere à dificuldade de responder à pergunta "o que é linguagem" e arrola nada menos que cinco respostas diferentes de importantes lingüistas. Também MOUNIN (1968) dedica um capítulo do seu Introdução à Lingüística para discutir os múltiplos usos desse termo. Para HJELMESLEV (1971), a linguagem é um sistema de signos. No Dicionário Enciclopédico das Ciências da Linguagem, DUCROT e TODOROV (1988, p. 9) iniciam a Introdução postulando a necessidade de definir um conceito de linguagem que será o fio condutor da obra:

Decidimos dar à palavra linguagem o sentido restrito - e banal - de "língua natural": não o de "sistema de signos", tão difundido em nossos dias. Não trataremos, pois, aqui, nem das línguas documentárias, nem das diferentes artes consideradas como linguagens, nem da ciência tomada como língua bem ou mal feita, nem da linguagem animal, gestual, etc. 
Neste mesmo sentido, ou seja, de língua ou língua natural, o termo é utilizado, em algum momento, por inúmeros autores, tais como BURKE e PORTER, 1993; GNERRE, 1987; FÁVERO e KOCH, 1994; ILARI, 1985; DACANAL, 1985, entre outros.

De modo geral, predominam, às vezes empregados de forma excludente, às vezes conjugadamente, dois sentidos mais costumeiros para o termo: sistema de signos e língua natural.

Embora as línguas constituam formas de linguagem verbal, esta não é redutível a uma língua. Por outro lado, o emprego do termo no sentido de sistema de signos, de conteúdo mais amplo, parece ser o que mais dá margem a equívocos, seja pela imprecisão do conceito de signo porventura adotado, seja porque não contempla a realidade essencial da linguagem, conforme veremos mais adiante.

Com efeito, o signo é elemento constitutivo da linguagem. Para a representação do mundo objetivo na consciência e para a realização do intercâmbio do conteúdo da consciência com seus semelhantes, os homens produzem códigos ou sistemas de signos arbitrários, sustentados por diferentes suportes materiais.

DUCROT e TODOROV, na obra já citada, definem o signo como "uma entidade que 1) pode tornar-se sensível, e 2) para um grupo definido de usuários assinala uma falta nela mesma" (com grifos no original). E, conforme ainda os autores, a parte do signo que pode tornar-se sensível denomina-se significante, enquanto a parte ausente, significado. A relação mantida por ambos consiste na significação. Explicando melhor os elementos dessa definição, esclarecem que, de fato, um signo pode existir sem estar perceptível, como é o caso das palavras de uma língua que, não tendo, permanentemente, uma existência perceptível, podem, no entanto, a qualquer momento tornarem-se perceptíveis. Esclarecem, ainda, que os signos só existem socialmente e têm um caráter convencional, institucional, logo, existem para um grupo definido de usuários que partilha tal convenção. Finalmente, o signo assinala uma falta do objeto perceptível por ele significado. Explicitam, a seguir, que o signo se assenta em uma tríade de polaridades: significante e significado; sensível e não-sensível; presença e ausência.

Entretanto, o signo assim definido não é, necessariamente, lingüístico, esclarecem. Para sê-lo, há de inscrever-se nas especificidades da linguagem verbal, quais sejam: a) o aspecto sistemático; b) a existência necessária de significação (no sentido de que a relação entre um significante e um significado é imotivada e, ao mesmo tempo, necessária); c) a secundaridade. 
A última especificidade - a secundaridade - constitui uma diferença qualitativa que distingue a linguagem verbal de todos os outros sistemas análogos. Ela contempla um conjunto de certas propriedades específicas da linguagem verbal, a saber:

a) pode-se utilizá-la [a linguagem verbal] para falar das próprias palavras que a constituem e, com muito mais razão, de outros sistemas de signos; b) pode-se produzir frases que recusem tanto a denotação quanto a representação: por exemplo, mentiras, perífrases, repetição de frases anteriores; c) pode-se utilizar as palavras num sentido que não é conhecido previamente pela comunidade lingüística, fazendo-se compreender graças ao contexto (DUCROT; TODOROV, 1988, p. 104).

Esclarecem, ainda, os autores, que, em presença apenas da primeira propriedade o que se tem é apenas um código; quando as duas primeiras propriedades estão presentes, estamos diante de um sistema de signos e não, ainda, da linguagem propriamente dita. Neste sentido, enfatizam que "a maioria dos sistemas significativos que nos rodeiam são mistos: são, ao mesmo tempo, códigos, sistemas de signos e sistemas simbólicos; mas nenhum deles possui todas as três propriedades da linguagem” (p. 105).

A carência de secundaridade em todos os demais sistemas significativos os faz tributários da linguagem verbal, obrigando-os a recorrer complementarmente a ela para realizar seu objetivo comunicacional.

Aceitas estas definições, evidencia-se impróprio o uso do termo linguagem para outras manifestações que, embora envolvam códigos e símbolos, não se constituem, de fato, como linguagem, no sentido mais rigoroso do termo.

Poder-se-ia argumentar que se trata de questão meramente semântica. Entretanto, há uma razão da maior relevância a exigir a precisão dessa categoria: trata-se das relações de interdependência entre linguagem, ideologia e consciência.

O reconhecimento da relação entre linguagem e consciência já é matéria de consenso no meio científico. Não significa, entretanto, que haja consenso acerca da natureza dessa relação. Nem isto seria possível, considerando o caráter interessado, classista, da ciência. 
Coerentemente com a orientação teórico-metodológica em que se apóia este trabalho, vamos buscar nos cientistas e pensadores de concepção materialista-histórica elementos para uma reflexão a respeito.

Para MARX e ENGELS (1998), há uma relação íntima entre consciência, pensamento e linguagem, que, por seu turno, têm sua existência determinada pela realidade social dos homens:

...[verificamos que] o homem tem também "consciência". Mas ela não existe à primeira vista como "pura" consciência. "O Espírito" tem como primeira característica a maldição de ser "oprimido" pela matéria, que aqui se apresenta sob a forma de camadas de ar, de sons, em resumo, sob a forma de linguagem. A linguagem é tão velha como a consciência - a linguagem é a consciência prática, a consciência real, que existe para todos os homens, e portanto, também para mim, e a linguagem resulta principalmente, tal como a consciência, da necessidade de intercâmbio com outros homens (...) Logo, a consciência é acima de tudo um produto social e mantém-se como tal, enquanto os homens existirem (p. 110).

Enquanto produtos sociais, consciência, pensamento e linguagem dimanam da produção material da existência. Por seu turno, a unidade da linguagem e do pensamento resulta da própria natureza do pensamento, ou seja, de sua imaterialidade. No processo social de produção da existência, os homens estabelecem entre si relações de produção que demandam intercâmbio, donde a origem da necessidade da linguagem é tida como possibilidade, ao mesmo tempo, de representação da realidade objetiva no cérebro e de exteriorização do pensamento. Essa possibilidade provém do caráter sígnico da linguagem, posto que o signo reflete a realidade objetiva no cérebro. O signo pode fazer penetrar no cérebro o "reflexo" de qualquer elemento objetivo da realidade, bem como, ao inverso, permite externalizar o conteúdo do pensamento. Assim, na expressão desses pensadores, "a linguagem é a realidade imediata do pensamento" (MARX; ENGELS, 1998, p. 110).

Entretanto, ao refletir a realidade, o signo pode, no dizer de Volochinov (apud BAKHTIN, 1986, p. 32), "ser-lhe fiel, ou apreendê-la de um ponto de vista específico". E, mais adiante, acrescenta que "o domínio do ideológico coincide com o domínio dos signos: são mutuamente correspondentes. Ali onde o signo se encontra, encontra-se também o ideológico. Tudo que é ideológico possui um valor semiótico" (com grifo no original). 
Desenvolvendo uma consistente crítica à filosofia idealista e à visão psicologista da cultura - as quais defendem que a ideologia é um fato subjetivo, limitado à consciência, e que a dimensão material do signo se reduz à condição de mero instrumento da subjetividade -, Volochinov aponta que, a despeito de suas profundas diferenças metodológicas, ambas as tendências incorrem num mesmo erro fundamental: situam a ideologia na consciência e, assim, transformam o estudo das ideologias em estudo da consciência e de suas leis.

Abraçando outra concepção acerca da ideologia, Volochinov afirma a natureza objetiva do signo e apóia neste pressuposto a explicação sobre a relação entre a realidade objetiva e a consciência. Diz ele:

Todo fenômeno que funciona como signo ideológico tem uma encarnação material, seja como som, como massa física, como cor, como movimento do corpo ou como outra coisa qualquer. Nesse sentido, a realidade do signo é totalmente objetiva(...) Um signo é um fenômeno do mundo exterior. O próprio signo e todos os seus efeitos (todas as ações, reações e novos signos que ele gera no meio social circundante) aparecem na experiência exterior.

A filosofia idealista e a visão psicologista da cultura situam a ideologia na consciência. Afirmam que a ideologia é um fato de consciência e que o aspecto exterior do signo é simplesmente um revestimento, um meio técnico de realização do efeito interior, isto é, da compreensão. O idealismo e o psicologismo esquecem que a própria compreensão não pode manifestar-se senão através de um material semiótico (por exemplo, o discurso interior) (p. 33).

E conclui, "a própria consciência só pode surgir e se afirmar como realidade mediante a encarnação material em signos" (VOLOCHINOV, apud BAKHTIN, 1986).

Por outro lado, os signos se realizam em um terreno interindividual, ou seja, no processo de intercâmbio lingüístico, de interação verbal entre uma e outra consciências individuais, de modo que "a consciência só se torna consciência quando se impregna de conteúdo ideológico (semiótico), e, conseqüentemente, somente no processo de interação verbal” (p. 34).

Daí a conclusão do autor de que a consciência individual nada pode explicar - ao contrário do que pretendem a filosofia idealista e à visão 
psicologista - mas ela própria deve ser explicada a partir do meio ideológico e social, pois "o signo não pode ser separado da situação social sem ver alterada sua natureza semiótica" (p. 62).

Apoiando-se em uma perspectiva social, afirma que a consciência não deriva diretamente da natureza, nem a ideologia deriva da consciência. Antes, a consciência adquire forma e existência nos signos criados, por um grupo organizado, no curso de suas relações sociais: "Os signos são o alimento da consciência individual, a matéria de seu desenvolvimento, e ela reflete sua lógica e suas leis. A lógica da consciência é a lógica da comunicação ideológica, da interação semiótica de um grupo social” (p. 36).

$\mathrm{E}$, mais adiante:

A realidade dos fenômenos ideológicos é a realidade objetiva dos signos sociais. As leis dessa realidade são as leis da comunicação semiótica e são diretamente determinadas pelo conjunto das leis sociais e econômicas. A realidade ideológica é uma superestrutura situada imediatamente acima da base econômica. A consciência individual não é o arquiteto dessa superestrutura ideológica, mas apenas um inquilino do edifício social dos signos ideológicos (p. 36).

O signo tem por função a significação. Esta constitui a expressão da relação do signo, como realidade isolada, com uma outra realidade, por ela substituível, representável, simbolizável. Destarte, enquanto propriedade relacional, a significação não pode ser apreendida dissociada do signo, nem da realidade objetiva que este representa. A significação, enfim, não tem existência em si mesma, como uma realidade isolada. O signo ideológico é, portanto, o território comum, tanto do psiquismo quanto da ideologia. É, como expressa Volochinov, um território concreto, sociológico e significante.

Em uma sociedade dividida em classes, o signo carrega consigo a marca dessa divisão. Volochinov desenvolve uma concepção da palavra como realidade dividida em duas faces, a cuja divisão está subordinada a significação. Depreende-se, daí, o caráter não neutro da palavra.

Em síntese, a linguagem, que é constitutiva da consciência, tem uma natureza ideológica posto tratar-se de atividade social e, enquanto tal, determinada por fatores sociais que emergem no processo de produção e, neste sentido, portadora das contradições inerentes à divisão de classes. 
Deste modo, em uma perspectiva transformadora, o aprendizado da linguagem, vale dizer, da língua, implica necessariamente a compreensão dessa natureza dividida do signo e o desvendamento do conteúdo ideológico da linguagem, a partir da própria compreensão da realidade contraditória do processo de produção classista. Implica, igualmente, entender que, tributários da realidade material, em um nível de mediação, e tributários da linguagem verbal, em outro, os sistemas de significados também não são neutros. O desvendamento de seu conteúdo ideológico, entretanto, articula-se, em uma relação de dependência, ao desvendamento possível no âmbito da consciência, que opera com elementos linguiístico. Assim, a subordinação das demais "linguagens" à língua, no processo de ensino-aprendizagem, não constitui demérito para aquelas. Antes, apresenta-se como condição mesma de realização daquela aprendizagem em um nível mais consistente e profundo.

Assim, considerando importante o alerta quanto a necessidade de os trabalhadores conhecerem os recursos, a lógica interna e as leis de funcionamento de todas as novas linguagens - vale dizer as Novas Tecnologias e os Meios de Comunicação de Massa -, cabe denunciar que, tal como vem sendo proposto (por exemplo, nos Parâmetros Curriculares), um nivelamento destas com a língua (ou linguagem propriamente dita) se assenta numa imprecisão que urge ser superada. O emprego de um termo impreciso para designar uma categoria de tal importância apresenta-se necessariamente deletério, seja por não explicitar com clareza o conteúdo que se almejava, seja porque cria um campo fértil para o vicejamento de formulações redutoras dessa categoria. Reducionismos estes claramente interessados, cujo conteúdo é a naturalização e/ou coisificação das relações sociais, como já mencionamos anteriormente. Tais reducionismos levam, como conseqüência, a práticas educativas também reducionistas.

É preciso, pois, considerar o novo em sua articulação com o velho conteúdo, ainda presente, da divisão de classes, como condição, inclusive, de um direcionamento mais claro para a luta transformadora. 


\section{REFERÊNCIAS}

BAKHTIN, M. Marxismo e Filosofia da Linguagem. São Paulo: Hucitec, 1986.

BENKO, G. Economia, espaço e globalização. São Paulo: Hucitec, 1999.

BURKE, P.; PORTER, R. (Org.). Linguagem, indivíduo e sociedade. São Paulo: Unesp, 1993.

DACANAL, J. H. Linguagem, poder e ensino da língua. Porto Alegre: Mercado Aberto, 1985.

DUCROT, O.; TODOROV, T. Dicionário enciclopédico das ciências da linguagem. São Paulo: Perspectiva, 1988.

FÁVERO, L. L.; KOCH, I. G. V. Lingüística textual: introdução. São Paulo: Cortez, 1994.

FERRETI, C. et al. (Orgs.). Novas tecnologias, trabalho e educação: um debate multidisciplinar. Petrópolis: Vozes, 1994.

FRIGOTTO, G. As mudanças tecnológicas e educação da classe trabalhadora: politecnia, polivalência ou qualificação profissional. In: MACHADO, L. R. S. et al. Trabalho e educação. Campinas: Papirus, Cedes; São Paulo: Ande, Anped, 1992. Coletânea CBE.

FRIGOTTO, G. (Org.). Educação e crise do trabalho: perspectivas de final de século. Petrópolis: Vozes, 2001.

GNERRE, M. Linguagem, escrita e poder. São Paulo: Martins Fontes, 1987.

HJELMSLEV, L. Prolégomènes à une theorie du langage. Paris: Minuit, 1971.

ILARI, R. A lingüística e o ensino da Língua Portuguesa. São Paulo: Martins Fontes, 1985.

KUENZER, A. Z. Ensino Médio e Profissional: as políticas do Estado neoliberal. São Paulo: Cortez, 1997.

. As mudanças no mundo do trabalho e a educação: novos desafios para a gestão. In: FERREIRA, N. C. Gestão democrática da educação: atuais tendências, novos desafios. São Paulo: Cortez, 1998.

. Educação profissional: categorias para uma nova pedagogia do trabalho. Boletim Técnico do Senac, Rio de Janeiro, v. 25, n. 2, maio/ago. 1999.

. (Org.). Ensino Médio: construindo uma proposta para os que vivem do trabalho. São Paulo: Cortez, 2001.

LÊNIN, V. I. Obras escolhidas. São Paulo: Alfa-Ômega, 1979. v. 1. 
LOPES, E. Fundamentos da lingüística contemporânea. São Paulo: Cultrix, 2000.

LYONS, J. Linguagem e lingüística: uma introdução. Rio de Janeiro: Zahar, 1985.

MACHADO, L. R. de S. Mudanças tecnológicas e a educação da classe trabalhadora. In: et al. Trabalho e educação. Campinas: Papirus, Cedes; São Paulo: Ande, Anped, 1992. Coletânea CBE.

MARX, K. O capital. São Paulo: Difel, 1982. Livro 1, v. 1.

; ENGELS, F. Manifesto do Partido Comunista. In: REIS FILHO, D. A. (Org.). $O$ Manifesto Comunista: 150 anos depois. Rio de Janeiro: Contraponto; São Paulo: Fundação Perseu Abramo, 1998.

MEC. Parâmetros Curriculares Nacionais. Brasília: Ministério da Educação, 1999. Disponível em: <www.mec.gov.br/sef/estrut2/pcn/downloads.asp> Acesso em: 20 mar. 2003.

MOUNIN, G. Introdução à lingüística. São Paulo: Martins Fontes, 1968.

ROSDOLSKY, R. Gênese e estrutura de O Capital de Karl Marx. Rio de Janeiro: Eduerj; Contraponto, 2001.

TENÓRIO, R. M. Cérebros e computadores: a complementaridade analógico-digital na informática e na educação. São Paulo: Escrituras, 1998.

VOGT, C. Por uma pragmática das representações. Discurso, São Paulo, n. 11, nov. 1979.

Texto recebido em 25 maio 2003

Texto aprovado em 05 set. 2003 